Revista Española de Filosofía Medieval, 3 (1996), pp. 147-158

\title{
UNIVERSIDAD MEDIEVAL Y ENCICLOPEDIA DEL SABER: IMPLICACIONES ANTROPOLÓGICAS
}

\author{
Xabier Andonegui \\ Universidad del País Vasco
}

\begin{abstract}
RESUMEN
Lejos de los tópicos sobre el llamado «oscurantismo» medieval, la dinámica global socio-cultural de los siglos XI-XIII es de signo inequívocamente humanista, aunque su principal problema reside en conservar la tradición cristiana heredada, actualizándola y finalmente enriqueciéndola con las aportaciones de la ciencia árabe y el pensamiento aristotélico conocido en su esplendor. La creación de la Universidad, la reestructuración de los saberes bajo la guía de la ciencia aristotélica, los conflictos recurrentes por mor de mantener la hegemonía de la teología en la formación del hombre medieval, se entienden mejor vistos desde la básica confrontación de dos concepciones del hombre en cuanto «imagen de Dios», una propendiendo a la sumisión y otra conducente a la autonomía. Entre ambas mediarán las grandes figuras: así Anselmo, Tomás o Escoto lo harán en distintos momentos del proceso y desde supuestos distintos, transmitiéndonos un modelo basado en la complementariedad-jerarquizada-de ambas perspectivas.
\end{abstract}

\section{ABSTRACT}

Far of the topics about the so called medieval «obscurantism», the global sociocultural dynamic of the XI-XIII centuries is unequivocally humanist, although its main problems consists in conserving the inherited Christian tradition, rejuvenating as well as enriching it with the arabian science and the aristotelian thought, known in their splendour. The creation of the University, the reconstruction of the knowledges with the guide of the Theology in the education of medieval man, can be better understood, looking at them from the basic confrontation of two conceptions of the man as «image of God»: one of them, tending to the submission, and the other one, tending to the autonomy. Between both tendencies, the great figures as Anselmo, Thomas or Scot will mediate an agreement. They do it in different moments of the process and from different suppositions. But they all transmit to us a model based in the complementary hierarchization of bot perspectives.

\section{ORGANIZACIÓN DEL SABER Y DINÁMICA SOCIO-CULTURAL}

Jacques Le Goff y Umberto Eco, estudiosos ambos del Medioevo, nos dan a entender que el mundo medieval, incluido el pensamiento que le caracteriza, no constituye ningún orden 
estático, sino que se halla surcado por poderosas corrientes que le hacen ser presa de un fuerte dinamismo, no exento de tensiones polares, pero cuyo sentido de conjunto puede establecerse bastante inequívocamente. ${ }^{1}$

Así, afirma U. Eco que la Edad Media, bajo una apariencia inmovilista, fue paradójicamente un momento de revolución cultural, justo por haberse hallado en la precisión de conservar, a su manera, la herencia del pasado: no mediante la hibernación, sino a través de nuevas y continuas traducciones y utilizaciones. De ahí la idea de un cierto paralelismo entre la Europa medieval y la sociedad contemporánea, de la que se ha dicho que vive una época de «transición permanente». Es más, Eco añade algo que nos importa particularmente, a saber: que el hombre medieval respondió a los desafíos de su época, entre otras cosas, inventando la Universidad.

J. Le Goff, coincide fundamentalmente con U. Eco, al tiempo que nos conduce, como de la mano, a concentrar la mirada en torno al punto que más nos interesa, en cuanto que viene a relacionar explícitamente el tema de la revolución cultural medieval con el surgir de la figura del intelectual y la subsiguiente creación de la Universidad.

Al observar que hoy la Edad Media empieza a suscitar renovado interés, y suponer que ello sea debido a que nuestra memoria selectiva descubre en ella ciertas afinidades con nuestro momento histórico, Le Goff aventura esta hipótesis: el Medioevo, en cuanto época de masas, debe de ejercer una particular atracción sobre el hombre contemporáneo que vive asimismo en una sociedad de masas. ${ }^{2}$ Ahora bien, la concentración de la población en núcleos urbanos, fenómeno típicamente medieval que hizo nacer nuestras ciudades, merece ser vista por nosotros en estrecha relación con importantes hechos que afectan a la vida intelectual: en efecto, es en íntima relación con la vida urbana como se origina en el Medioevo el sistema universitario cuyo alcance llega hasta nosotros. ${ }^{3}$

De hecho, la organización universitaria de los saberes y el nuevo estatuto que reciben los que allí se imparten, son componentes de la revolución cultural a la que hacía referencia U. Eco. Le Goff no deja de señalar «la importancia, en el ámbito de la historia intelectual y, de manera más genérica, en el ámbito de la historia, de las evoluciones o revoluciones epistemológicas que de vez en cuando organizan nuevos sistemas de clasificación de las ciencias»; y añade a continuación: «Si esto ocurre, especialmente en el mundo occidental, se debe sin duda a la existencia de instituciones que han elaborado e impuesto a la vez estos nuevos sistemas de clasificación». ${ }^{4}$ Simultáneamente, subraya Le Goff la máxima actualidad que reviste hoy tal cuestión: como que están surgiendo nuevas disciplinas y transformándose las relaciones entre

1 Eco, U., "La Edad Media ha comenzado ya", Eco, U., Colombo, F., etc., La nueva Edad Media, Madrid, Alianza Editorial, 1974, p. 9-34; Le Goff, J., Entrevista sobre la historia, a cargo de F. Maiello, Valencia, Edicions Alfons el Magnànim, 1988.

2 Mientras que la Antigüedad nos llega como la época de las élites, como un período aristocrático, las "masas" a las que nuestra sociedad actual es tan sensible, se encuentran ya en la Edad Media Cf.Ibid. 101; 104-107.

3 En efecto, nuestro sistema de enseñanza y todo lo que ha quedado como base de nuestra formación proviene de la Edad Media.

4 Le Goff, Ibid.. 31-32. 
ellas; nos basta para tener constancia de ello atender a las variaciones en los programas escolares y universitarios,

Ahora que - sugiere - una investigación sobre el tema debería tener en cuenta la necesidad que hay de explicitar los interrogantes que con frecuencia permanecen implícitos en cualquier tipo de discurso sobre las relaciones entre las ciencias; ya que es frecuente - dicehablar acerca de las diversas disciplinas como si se tratara de ideas que vagasen por el mundo, y no en cambio de clasificaciones científicas tras las cuales se hallan organizaciones sociales.

Valga recordar a este respecto la perspectiva genérica del autor sobre los grupos de presión que luchan por condicionar el futuro de las sociedades orientando en un sentido determinado su búsqueda colectiva de identidad. ${ }^{5}$ De ahí que le resulte inexplicable la propensión de la gente de hoy a olvidar que un fenómeno tan específicamente occidental como éste de la elaboración de la división de las ciencias y determinación de las relaciones que les vinculan entre sí, trae su origen del Medioevo; y a pasar por alto el hecho capital por el que una doctrina de origen aristotélico sobre la subdivisión de los saberes, entró en el punto de mira organizativo de las élites medievales, al apercibirse de la relación manifiesta que ella guarda con el destino de los procesos socio-culturales en curso. Así, pues, el contexto y la manera misma cómo de vez en cuando surgen nuevas disciplinas o se transforman las relaciones entre ellas, lejos de testimoniar únicamente la movilidad de lo histórico en general, constituyen un fenómeno de primera importancia, que reclama un análisis interpretativo sobre el significado profundo de dichos cambios y acerca de los efectos previsibles a que se destinan. Una de las etapas más representativas a este respecto sería, según Le Goff, la que se observa durante los siglos XII y XIII. ${ }^{6}$ En particular, cree que una de las cosas a comprender con mayor profundidad sería el por qué, durante los siglos XII y XIII, la teología fue la ciencia que llegó a tener un papel estelar, y por qué lo más significativo de la evolución científica correspondiente puede decirse que se halla constituida por la concepción como ciencia de la misma teología. Cosa que, a su vez, cobra una dimensión del todo particular al tratarse de una transformación, no sólo ideológica sino profesional; gracias a ella pudo la teología terciar en la actividad científica de la época ajustándose ella misma en lo posible a un modelo científico. Se trata, pues, de un tema que merece investigación.?

5 Cosa que tiene lugar normalmente mediante exclusión o inclusión de elementos y actitudes provenientes de una o más tradiciones, en consonancia con las modificaciones que se desean inducir. La producción de la historia viene a ser siempre, según Le Goff, una forma de poder, y una baza del poder que, en cualquier sociedad, se expresa particularmente como intento consciente o inconsciente de proyectar una imagen sobre el futuro. De ahí la lucha que necesariamente se da por la dominación del recuerdo y de la tradición, lo que se traduce en una manipulación de la memoria. Ibid., 85. Cf. también, Le Goff, J., Histoire et mémoire, Paris, Gallimard, 1988, pp. 174-175; $45 ; 75$.

6 En efecto, piensa que para poder cerciorarse en el momento actual de por dónde sopla el viento de la reorganización de las disciplina, e incluso a fin de comprender hacia dónde habría que orientar el cambio, puede ser de gran ayuda el retomar los grandes momentos históricos en que se han producido los fenómenos concernientes, que son, los siglos XII-XIII, el Renacimiento, y el siglo XIX. Cf. Ibid., pp. 32-33.

7 lbid.. pp. 38. 


\section{IDEAL RACIONAL Y ANTROPOLOGÍA EN EL MEDIOEVO}

Comencemos por decir que el tiempo que transcurre entre el s. XII y el XIII es un período donde florecen toda clase de novedades. ${ }^{8}$ En efecto, muchas de las cosas que en el curso de estos siglos suceden tienen como denominador común la recuperación de la iniciativa por parte del individuo de las distintas clases sociales. Ello tiene lugar en el terreno mercantil y de movilidad espacial (las ferias), en el terreno social y político (las organizaciones gremiales y comunales), en el terreno de la enseñanza (nuevas escuelas para nuevas necesidades). En el ámbito intelectual, se asiste al surgimiento de maestros como Abelardo, que gracias a su fuerte individualidad y sus cualidades intelectuales y didácticas, atraen gran número de discípulos que le siguen de escuela en escuela. En el ámbito jurídico como luego en otros, las ideas han empezado a ser rentables y la cultura intelectual a convertirse en palanca de promoción social. Es el momento de que haga su aparición la nueva figura y profesión del intelectual; y de que el perfil del intelectual como artesano de las ideas en función de la investigación y la enseñanza, halle reconocimiento en la sociedad. ${ }^{9}$

A no tardar, de entre el proliferar de las escuelas en el siglo XII, algunas de ellas, primero en Bolonia y luego en París, llegaron a adquirir gran renombre. Hasta que, al fin, la extraordinaria afluencia de maestros y estudiantes a las mismas, desbordó la oferta primitivamente existente y dio lugar al nacimiento de la organización universitaria; ésta, al gran contingente de maestros y estudiantes cuyo establecimiento en determinados sectores de la ciudad era ya un hecho, añadía el nuevo armazón institucional unitario capaz de congregar a la totalidad de los maestros y del alumnado: universitas magistrorum et studentium.

Pero la era de las Universidades traía asimismo aparejada la transformación del saber religioso, junto con la nueva y explícita organización de los saberes en su conjunto. En concreto, la recuperación de la cultura religiosa por parte del espíritu de iniciativa y autonomía propios de la época hubo de recibir distintas expresiones, entre ellas, aquélla que la constituía en grandiosa elaboración y sistematización intelectual.

Pieza importante que disponía, de tiempo atrás, a la acogida de los cambios implicados por esa gran obra de la razón al servicio de la fe, era la generalización entre los intelectuales

8 Así, se dan innovaciones técnicas en el mundo rural (caballo de tiro, arado de ruedas, generalización del molino de agua); innovaciones asimismo en un orden distinto, como el hecho de que probablemente la población se triplicase durante este período, o el que nacieran las ciudades en el sentido moderno, ya no sólo como administrativas, políticas o militares, sino como fundamentalmente fabriles y comerciales al estilo de las nuestras, en cuyo interior se perfilan y emergen nuevas clases sociales. Ahora bien, en relación íntima con estas transformaciones es como emerge asimismo una nueva cultura en su aspecto intelectual, y sus manifestaciones más destacadas vienen a ser: el nacimiento de las escuelas y de las universidades y: juntamente, el nacimiento de una nueva clasificación de las ciencias. El despertar intelectual y el portentoso desarrollo sucesivo se enmarcan, pues, en el conjunto de un período de gran vitalidad, en el que el s.XI marca el impulso inicial, el s. XII la aceleración y el s. XIII la institucionalización de ese impulso (Cf. Ibíd; pp. 69-71). Advierte el autor que, aunque sea un abuso de lenguaje decir que el Renacimiento comienza en la Edad Media, no obstante lo que sí resulta patente es que el Renacimiento no representa en la evolución histórica una cesura tan grande como pensaban los mismos renacentistas, creadores dé la noción de Edad Media.

9 Le Goff, J., Los intelectuales en la Edad Media. Barcelona. Gedisa, 1986. 
de una concepción del ser humano, apta para justificar y promover tales desarrollos: se trataba de un pensamiento antropológico remozado en una dirección inequívocamente humanista, el cual hallaba su centro de gravedad en la noción del hombre como ser racional. Se trata de una concepción que subrayaba la afinidad del hombre con el ser angélico apartándolo del animal como antítesis de lo humano, para acabar cifrando en sus facultades racionales la condición de imagen de Dios. Bajo esta perspectiva era cómo los intelectuales del s.XI y XII aspiraban a poder conciliar los datos de la fe tradicional con el ideal racional progresivamente asumido. ${ }^{10}$ Pero ello significaba retocar en aspectos importantes la concepción cristiana tradicional del hombre heredada por el Medioevo, abriéndola cada vez más al influjo de los autores griegos y árabes. ${ }^{11}$ De hecho, las iniciativas que Abelardo adoptó en cuanto a hacer teología desde su propia perspectiva, fueron contestadas por san Bernardo y condenadas bajo su influencia. Así y todo, la aportación abelardiana sería asumida como importante por el nuevo método que seguiría la teología en el siglo XIII; señal evidente de que en la sensibilidad de Abelardo afloraba un exigencia imprescriptible de los nuevos tiempos. ${ }^{12}$ Pero sólo San

10 Pedo Abelardo mostrará viva conciencia de que sus estudiantes ya no podían creer sin comprender el sentido auténtico de lo creído; y que obrar de otro modo sería ceder en su dignidad de seres racionales hechos a imagen de Dios, aceptando dejarse llevar a ciegas por la autoridad. Un texto donde idéntica exigencia aparece expresada con agudeza es el de Adelardo de Bath, un intelectual de la escuela de Chartres, traductor filósofo y viajero por España, quien a instancias de un tradicionalista, responde al consabido tema acerca de lo que distingue al hombre del animal, al tiempo que utiliza polémicamente su respuesta contra el interrogador «Me es difícil discutir sobre animales. En efecto, aprendi de mis maestros árabes a tomar la razón como guía, en tanto que tú te contentas, como cautivo, con seguir la cadena de la autoridad basada en fábulas. iQué otro nombre darle a la autoridad que el de cadena! Asi como los animales estúpidos sorr conducidos mediante una cadena y no saben ni adónde se los conduce, ni para qué se los conduce, pues se limitan a seguir la cadena que los sujeta, asi también la mayoria de vosotros sois prisioneros de una credulidad animal y os dejáis conducir encadenados a creencias peligrosas por la autoridad de lo que está escrito». Citado por Le Goff. Ibíd., pp. 62-63.

11 Estas implicaciones las intuía de maravilla san Bernardo protagonista de la reforma monástica en el siglo XII, cuando sostenía que no existe necesidad alguna de los inventos de la razón; como que la tarea que se habían asignado los monjes consistía precisamente en la restauración del hombre que, creado libre a imagen de Dios, debido a un mal uso de esa libertad indestructible en que consiste su dignidad, había visto decaer en sí mismo la semejanza con Dios que le caracteriza, convertido en desemejante por el mal y el sufrimiento. Importa, consiguientemente, caer en la cuenta de que, para san Bernardo, la «imagen y semejanza» de Dios, se juega íntegramente en el orden de la libertad; de tal suerte que sólo eligiendo amar a Dios sobre todas las cosas podrá el hombre ponerse en camino de recobrar la condición originaria en su integridad. Se explica que, frente a las escuelas donde se enseña a Platón o a Aristóteles. Bernardô proponga la vuelta a la «escuela primitiva de la Iglesia» donde el maestro es Cristo; que a eso se encamina la vida del claustro que organizó san Benito como un aprendizaje de la caridad a través de los doce grados de humildad. Como bien se ve, este programa presupone un discernimiento de lo que el hombre es en línea con la tradición de la Iglesia, y de esa manera pretende alcanzar el auténtico saber de sí mismo que venga a dar cumplimiento al antiguo adagio del nosce teipsum. En contraste con los filósofos, para quienes el espíritu humano se asemeja a Dios en su ser inteligencia, de tal forma que sólo obtiene su plenitud autorrealizándose como tal mediante el conocimiento, según la espiritualidad monástica. el ser humano sólo recobrará la semejanza de Dios cuando éste tenga a bien otorgárselo, tras haber permanecido al interior de la fe con la actitud de humildad propia de un espíritu confrontado constantemente con un objeto velado; y aun entonces; sólo le será dable alcanzar un cierto conocimiento místico de tal objeto, bien lejos de cualquier intuición intelectual, la cual nos está reservada para la otra vida Cf. Vignaux. P., El pensamiento en la Edad Media, Madrid. F.C. E., 1985, pp. 55-58.

12 Es verosímil que un Abelardo, llevado de su genio lógico y de su preferencia y dedicación intensiva a la dialéctica, acentuara en su teología más la parte de la inteligencia que la de la fe, con peligro de alterar el delicado 
Anselmo lograría ejemplificar un primer audaz equilibrio entre ambos puntos de vista presuntamente incompatibles, como justa actitud intelectual que brota de la antropología del homo viator. ${ }^{13}$

Con ocasión de la organización de la Universidad vendrían a proyectarse en el plano institucional de la misma esas mismas tensiones o polaridades de base. La Universidad era, por una parte, creación inédita del orden social nuevo. Pero también una institución, de las más significativas, de la cristiandad, con lo que ello implicaba de ingerencia por parte de los obispos locales y el Papado. Estos consideraban a la corporación intelectual de la ciudad como parte cualificada del cuerpo eclesial, con su «oficio» especializado, y sus derechos y libertades anejos. Desde ahí se comprende que la Facultad de teología pretendiera ser también, y fuera de hecho, como el alma de esa institución universitaria, así como la razón principal de la jurisdicción que la Iglesia reclamaba sobre ella. Aunque muy pronto, debido al número y calidad de sus miembros, la Universidad se manifestaría como un tercer poder, junto al poder real y el eclesiástico, justo en la medida en que iba creciendo su autonomía, con el favor de los privilegios arrancados a los otros dos poderes aprovechando las diferencias entre ambos.

Esta situación confería a la Universidad, según señala Le Goff, una ambigüedad de carácter estructural (que venía dada por la peculiaridad de su dependencia eclesiástica y el talante laico de su inspiración) ${ }^{1+}$ la cual ambigüedad resulta más sorprendente si cabe, por lo que entraña de tener que unir dependencia con autonomía, cuando en particular se trata de la Facultad de teología.

equilibrio que teóricamente aceptaba sin duda cual regla fundamental del trabàjo teológico. Se intuye que en algo de esto hubieron de basarse las acusaciones de san Bernardo, de «querer comprenderlo todo"; porque, en efecto, en la perspectiva de Abelardo los dogmas de la fe, más que como sobrecogedoras verdades sobrenaturales que apenas logra balbucir el lenguaje humano, aparecían como otras tantas proposiciones y datos en cuya comprensión ha de ejercitarse èl ingenio humano poniendo en juego las reglas de la gramática y de la lógica.

13 El nos brinda el primer ejemplo elocuente de un pensamiento que se inicia en forma de plegaria y: sin solución de continuidad, se desarrolla con los medios lógicos de la argumentación más estricta. Nos coloca así sin más preámbulos frente a la situación humana fundamental de la que brota: justificándola, no ya sólo la especulación anselmiana, sino también la de la escolástica posterior: es la situación dramática del pensamiento humano, forzado a moverse entre la fe y la visión, en razón del deseo de ver el rostro divino que le acucia, al haber sido creado precisamente para esa visión. Por eso mismo, Anselmo significa una invitación a mirar con escepticismo el valor de la oposición comúnmente aceptada entre mística y escolástica, entre sentido religioso y rigor lógico. Con san Anselmo la fe se coloca, no en las antípodas, sino en el punto de partida de una búsqueda intelectual mediante la que el hombre espera recobrar algo del conocimiento humano anterior a la caída. Sólo que consciente de que se trata de una obra de re-creación sustentada en la gracia sobrenatural, la tarea del especulativo se abre con la oración, en reconocimiento práctico de que el primer paso lo ha de dar la fe: ya que el hombre no puede buscar a Dios si Dios no le enseña, ni encontrar a Dios si éste no se le muestra. Ibid., pp. 32-34.

14 Le Goff. J., Los intelectuales en la Edad Media, Barcelona, Gedisa, 1986, pp. 76-77. Cf. Knowles, D., L'evoluzione del pensiero medievale, Bologna, Il Mulino, 1984, pp. 219-224. 


\section{LA REMODELACIÓN DE LOS SABERES Y SU PROBLEMÁTICA}

\subsection{El sentido de la nueva Teología.}

Antes que nada es preciso hacer hincapié en lo revolucionario del hecho de que una corporación de profesores tuviera en la Iglesia cargo y mandato de enseñar la doctrina revelada (cosa hasta entonces reservada a los obispos y a sus delegados para la enseñanza catequética; y ello con derecho propio y exclusivo de elaborar los programas y de conferir los grados académicos con validez universal: licentia ubique docendi.

Es, pues, de un cuerpo de profesionales de lo que se trata, dedicados como tales a la elaboración de un saber y a su transmisión; son ellos los que ahora reciben el encargo de enseñar en la Iglesia la doctrina revelada. Profesores, por otra parte, cuyo título jurídico depende de la corporación universitaria, dejando de ser, por tanto, su actividad una función jerárquica para entrar casi de lleno en el ámbito profesional. Es decir, que con el favor del prestigio social inédito de que gozan los magistri, se crea un nuevo tipo de magisterio teológico, que ya no es del tipo de los obispos-doctores de la edad patrística y menos aún del de los obispos-señores de la época feudal. De manera que, en adelante, la función magisterial en la iglesia occidental se separa de hecho de la sacramental y de la responsabilidad de gobierno. En consecuencia, surge como contradistinta de la autoridad magisterial la autoridad del teólogo, que se deja guiar, en una medida importante aunque no exclusiva, por criterios racionales y practica los correspondientes métodos actualizándolos según pide la cultura de la época.

Desde el punto de vista eclesial, la creación de la universidad significa, por lo mismo, que el centro de gravedad de la elaboración de la cultura cristiana, se desplaza del ámbito intraeclesial recoleto de las escuelas conventuales y catedrales, donde la preocupación espiritual y pastoral es prevalente, para salir al espacio abierto del ámbito institucional universitario de nueva creación. ${ }^{15}$

Hay que entender este importante giro como fruto de la respuesta audaz dada por los teólogos al desafío de la sociedad postfeudal y su cultura. El objetivo perseguido consiste en remediar la debilidad histórica de que adolece la cultura sagrada tradicional de la sacra pagi$n a$ frente al prestigio de la cultura científica y filosófica en alza. Y la tarea asumida consiste en la elaboración de la doctrina sacra poniendo el acento en la organización conceptual de la reflexión teológica y no ya en la base textual bíblica objeto de comentario. El modelo de referencia, así metodológico como sistemático, para la adaptación científica de la teología fue Aristóteles; sobre todo fue su Física la que vino a proporcionar el nuevo andamiaje cosmológico, en sustitución de una cosmología bíblica de caracteres imprecisos y fantásticos. La teología abandona de este modo la forma narrativa practicada anteriormente y la sustituye por la forma sistemática, a modo de cuestiones, muchas de las cuales no proceden ya en su formu-

15 Alberigo, G., "Sviluppo e caratteri della teologia como scienza", Cristianesimo nella storia, 11 (1990), pp. 257-274. 
lación de la necesidad intrínseca de comprender el texto sagrado, sino que vienen impuestas por las exigencias de compaginarlo con el nuevo marco cosmovisivo adoptado. ${ }^{16}$

Se entiende, pues, el por qué del nuevo ideal científico perseguido por la teología en el s. XIII: desde que se siente que la cultura sagrada ya no satisface las exigencias culturales que se han abierto paso con la masiva recepción de Aristóteles, se trabaja para que halle acomodo en el nuevo clima científico dominado por la epistemología del Estagirita; y como consecuencia, se problematiza su concepto, a la par que se tematiza su estatuto científico y se transforman sus métodos. Al obrar así se daba a entender que la cultura de la fe era capaz de asumir lo humano válido que emerge en cada momento histórico; y que la forma de cultura cristiana adecuada a cada época no se construye exclusivamente de manera repetitiva, a golpe de autoridad y de tradición, sino que ha de hacerlo remitiéndose asimismo a la autoridad de la razón; de tal suerte que, por el mismo hecho, quedaba consagrada la autoridad complementaria de los teólogos sobre las cosas de la fe. El estreno de este nuevo tipo de autoridad el cual, lejos de excluir, implica la libertad de investigación e incluye entre sus métodos la libre discusión, supuso la reactualización en plena época medieval de aquél que fue momento constitutivo de la racionalidad occidental, cuando en Grecia nacieron juntas filosofía y autonomía.

\subsection{Enciclopedia del saber y antropología}

Ahora bien, también es cierto que la Universidad medieval, en la visión que de ella nos ofrece el paradigma parisino, revela a la mirada atenta otra vertiente suya no menos importante, dadas las implicaciones que la estructura y organización del saber tienen en relación con la comprensión y promoción del ser humano. Bajo este nuevo aspecto, la institución universitaria medieval presenta un aspecto de interpelación y desafío, si la enfrentamos con los hábitos que caracterizan a la mente moderna.

En el cristianismo latino la dogmática cristiana se transmitía con inclusión de un soporte filosófico constituido por la comprensión previa agustiniana de la verdad y la racionalidad, presuntamente inconmensurable con otras concepciones de origen pagano, sobre todo aristotélico. ${ }^{17}$ Fiel a esa tradición, la teología del siglo XII conoció un nuevo género literario dirigido a proporcionar una visión general integradora del conocimiento y de la investigación, anticipando de esa manera un cierto diseño enciclopédico de los saberes. Así la obra, en ese sentido, ejemplar de Hugo de San Víctor tenía como propósito manifiesto el de conseguir «la subordinación de todo aprendizaje a la lectura de la Escritura, para que el èstudio tuviera como resultado el perfeccionamiento de la práctica». ${ }^{18} \mathrm{De}$ tal manera que el orden por él impuesto a los estudios con tal fin vino a constituirse en un precedente clave a la hora de diseñar posteriormente la institución académica o el plan de estudios correspondiente.

16 Gregory, T., "Escatologia e Aristotelismo nella scolastica medievale", Giornale critico della Filosofia italiana, 40 (1961), pp. 163-174. Cf. Andonegui, J.,"Nacimiento y orientación de la Escuela Franciscana": Scriptorium Victoriense 34 (1987) 135-186. Cf.: pp. 147-151.

17 Macintyre, A., Tres versiones rivales de la ética., Madrid, Rialp, 1992, pp. 142-143.

18 Ibid. pp. 132. 
En efecto, según recientes investigaciones, no se explicaría la peculiaridad de la Universidad de París (a diferencia de la de Bolonia, por ejemplo), en lo que se refiere a sus formas de organización y a su plan de estudios, si no es como fruto de un debate sobre los ideales educativos partiendo como base de la convicción de que todo lo útil debe subordinarse a la búsqueda de la perfección humana. La opción consiguiente a un debate así planteado habría hecho de la universidad parisiense una universidad agustiniana orientada a la síntesis comprensiva del saber antiguo y el nuevo, de acuerdo con un orden regido por las típicas concepciones agustinianas de la investigación moral y de la racionalidad, todo ello afianzado sobre bases institucionales adaptadas a esa tarea de conjunto. Así se explicaría, en particular, el que toda la educación en París estuviera dirigida y subordinada al estudio de la teología; cosa que en alguna medida (a determinar) equivalía a dar por sentado el que la auténtica racionalidad forzosamente ha de entenderse como interior a un sistema de creencias y de prácticas, tal como lo profesa nuclearmente la versión agustiniana de la misma. ${ }^{19}$

Prueba de ello es la gran crisis de la universidad parisiense del siglo XIII, que tomó cuerpo en el enfrentamiento entre la Facultad de Artes y la de Teología; por encima de importantes roces en punto a cuestiones doctrinales particulares entre el pensamiento tradicional y un aristotelismo que se pretendía consecuente, dicha crisis comportaba el más fundamental litigio, que versaba sobre la estructura del conocimiento, así como sobre la organización de la investigación. De hecho, avisos y prohibiciones de la autoridad eclesiástica desde la primera mitad del siglo XIII sobre la enseñanza de Aristóteles habían tratado de evitar que se pusiera en cuestión la organización y estructura establecidas de la investigación, y en especial, la relación hegemónica de la teología con las otras disciplinas dentro de esa organización y estructura. Pero la crisis llegó no obstante, coincidiendo con el momento en que el corpus aristotélico era asumido como un todo para el estudio y la enseñanza de la Facultad de Artes. Por el mismo hecho ésta dejaba de ser una mera facultad preparatoria y se arrogaba, el poder pronunciarse sobre una amplia serie de cuestiones de ética, política, psicología y metafísica, que hasta entonces habían sido de exclusiva competencia de la teología. El nuevo estado de cosas presentaba de esta suerte todos los visos de una flagrante violación de la división agustiniana del trabajo intelectual y parecía desafiar no sólo a las disposiciones institucionales de la Universidad de París, sino a los supuestos intelectuales agustinianos de esas disposiciones.

Surgía así el dilema agustiniano: negarse a integrar el corpus aristotélico y su enseñanza en el plan de estudios equivalía a renunciar a la pretensión de que la teología puede realmente ordenar y dirigir a las otras ciencias y artes seculares, asumiendo la validez de sus puntos de vista metódicos e integrándolos en una unidad sistemática; por otra parte, aceptar sin más el corpus aristotélico en el plan de estudios dejándose guiar por la visión de las cosas que nos transmite, semejaba introducir una cuña de incoherencia en las estructuras del conocimiento y de la enseñanza garantizadas mediante la más prolongada y autorizada tradición. ${ }^{20}$

19 Ibid., pp. 132-133.

20 Ibid., pp. 144-145. 
De manera análoga a lo hecho con anterioridad por san Anselmo, Tomás de Aquino habría tratado de conciliar ambos polos, corrigiendo para ello la unilateralidad inherente a posiciones extremas. Así, en la línea de su predecesor y maestro Alberto Magno -él mismo de inspiración agustiniana-,Tomás habría consagrado la autonomía de la filosofía sobreponiéndose a la pendiente agustinista hacia el exclusivismo religioso el cual, al depotenciar el valor y autonomía del entendimiento creado, calumnia sin proponérselo a su Creador; por lo que el Aquinate no habría tenido inconveniente en reconocer el primado del magisterio aristotélico en todo lo concerniente a la explicación de los procesos naturales que dicen relación al conocimiento y al saber. ${ }^{21}$ Resultado entonces de esta toma de posición habría sido el abandono de la postura consistente en afirmar una única Verdad de la que sólo el teólogo podría hacer gala; asimismo quedaría descalificada la posición supuestamente averroísta que no vería más salida que la de una doble verdad, fruto de absolutizar la autonomía de la filosofía en independencia. En cambio, la postura equilibrada y conciliadora de Tomás se basaría en la admisión de dos perspectivas complementarias e irreductibles sobre la única Verdad, a sabiendas de que ninguna aproximación humana a la misma puede alardear de un carácter exhaustivo a todos los efectos. La configuración empero de la síntesis suprema vendría dada por la Revelación, única capaz de sugerirnos a los humanos la auténtica perspectiva de totalidad que el entendimiento humano de por sí solo no alcanza; salvo siempre que la credibilidad y valor de universalidad inherentes al conjunto podrían todavía en algún modo ser controlados por la razón filosófica, haciendo que no falte en la construcción sistemática aquel orden de verdades de dominio común entre filosofía y teología (los preambula fidei), llamados a operar como eslabón intermedio entre ellas. De esta suerte, Tomás se habría ingeniado para mantener la unidad enciclopédica del saber bajo hegemonía de la teología, considerada como lo irrenunciable del agustinismo; y habría intentado formular esa unidad, legitimando el carácter científico de la teología mediante el recurso a la teoría aristotélica de la subordinación de las ciencias. Se trató empero de una solución poco satisfactoria desde el punto de vista racional estricto, hasta el punto de que sus mismos discípulos lo reconocieron así.'-2 No extrañará entonces la afirmación vertida por H. Duméry en su Critique et Religion, quien apoyándose en una frase de Blondel dice: «El espíritu filosófico que engendró la Escolástica fue el mismo que se armó contra ella», refiriéndose al hecho constatable por el que la filosofía que Tomás declaró autónoma y subordinó a la teología, olvidó pronto su subordinación para no retener más que su autonomía. ${ }^{23}$ La deriva en este sentido dirá McIntyre- comenzaría por sus propios discípulos sin esperar a más tarde. ${ }^{2+}$

21 Ibid.: pp. 162-163; p. 171.

22 Cf., mis artículos: "Aristotelismo y agustinismo previos a Escoto», Scriptorium Victoriense. 35 (1988), pp. 113-117; «Teología como ciencia. Aspectos peculiares del planteamiento escotista», Scriptorium Victoriense, 36 (1989), pp. $420-424$.

23. Duméry, H., Critique et religion, Paris, Sedes, 1957, p. 84.

24 Así lo mostraría, según este autor (Ibid.. 173; 207) el hecho de que la enseñanza tomista no se preocupó mínimamente de salvaguardar, como condición previa e indispensable para captar el auténtico sentido de la obra de Tomás, la perspectiva unitaria que éste cuidadosamente le confirió, por ejemplo, al redactar la Summa. 
El mismo autor sugiere que los esfuerzos de Escoto corrieron la misma suerte, ya que también él, paradójicamente, habría asumido asimismo y potenciado la autonomía del método filosófico. ${ }^{25}$ Sin duda, hay razón para afirmarlo así, en cuanto que Escoto marcó, más que Tomás, las ruptura ente nuestra teología y la teología de los bienaventurados, entre las verdades que la razón alcanza y las que sólo son alcanzables mediante la revelación, entre la imperfección de nuestro conocimiento abstracto y aquél, de momento impracticable, que sin embargo nos corresponde de derecho e incluye la intuición del singular. No hay duda que en los tiempos posteriores a Escoto, sobre todo siguiendo la vía que abriera Ockham, haya venido a subrayarse esa línea de fuga escéptica que conduce al desarrollo cada vez más autónomo de la ciencia humana, a la vez que insiste en el carácter heterogéneo y el talante más o menos fideísta de las verdades pertenecientes al ámbito teológico.

Sin embargo, al escotismo de Duns Escoto le es esencial el empeño por establecer y garantizar la continuidad de filosofía y teología al interior de un proyecto unitario del saber, de carácter consciente y explícitamente agustiniano, como corresponde a la tradición de su Escuela. Pero tal proyecto difiere de modo importante del de Tomás de Aquino. La nueva perspectiva que Duns Escoto inaugura a fin de poder establecer con toda garantía la conexión deseada entre las dos la podríamos denominar «existencial». En el sentido de que se niega a hacer un discurso acerca del hombre y de sus facultades cognoscitivas y volitivas, así como de los distintos saberes que le conciernen, basado en consideraciones acerca de la naturaleza humana en general, como lo podría hacer un Aristóteles a partir de los datos comunes de la experiencia humana actual, tras tomarlos por expresión de lo humano en cuanto tal. Duns Escoto parte más bien de considerar al hombre en su ser concreto histórico — pro statu isto — mientras juega al mismo tiempo la baza de las posibilidades que le definen en cuanto naturaleza absoluta, dado que espera su definitiva realización en otro mundo que éste. En ese punto Escoto se muestra digno continuador de la antropología del homo viator que ya divisábamos en la base de la síntesis anselmiana; pero la intterpreta en forma distinta de Tomás, quien intentó elaborar la conexión entre filosofía y teología manteniéndose en un plano epistemológico estricto, de corte aristotélico.

Apuntábamos antes que el intento de justificación epistemológica de la teología como ciencia, no obstante lo ingenioso de la solución proyectada por Tomás aprovechando al efecto la noción aristotélica de «subalternación», pareció no obstante carente del rigor necesario a sus propios discípulos. En cambio, pudiera ser que el camino elegido por Escoto de la desabsolutización de la perspectiva epistemológica sobre la base del estudio del hombre histórico y de las paradojas que el mismo entraña, estuviera llamada a cosechar un éxito más verdadero, si bien más modesto; con la ventaja añadida de poder así mediar dialécticamente las dos antropologías en litigio desde el siglo XII o antes, en cuyo antagonismo hemos reconocido la infraestructura de las tensiones de la cultura y de las instituciones medievales, tal la Universidad. Desde el nuevo punto de vista, la complementariedad de filosofía y teología dejaría de basar- 
se - como sucede en Tomás - en una supuesta suficiencia científica de cada una de ellas, para fundarse más bien en la insuficiencia relativa de cada una, considerada su aportación a la cuestión antropológico-real, a saber: la de clarificarse acerca del ser del hombre en cuanto a su destino, poderes, posibilidades y exigencias, contando para ello con la rica experiencia acumulada por el ser humano en el transcurso de su historia. Desde este punto de vista, la convergencia medieval de dependencia y autonomía que se materializa en una institución universitaria que establece la coordinación obligatoria de filosofía y teología, no pierde, es cierto, su carácter tensional; pero sí que pierde el inconveniente supuesto de su impresentable justificación teórica.

De tal suerte, que el círculo creado entre autonomía racional y dependencia con respecto a la tradición religiosa, deja ya de presentar el carácter de un círculo vicioso, y comienza a insinuarse ante nuestros ojos como el carácter normal que ha de revestir la comprensión antropológica del ser humano, dado que ésta se enraíza en la tensión polar que recorre por entero el pensamiento occidental, como fruto de la convergencia de sus dos tradiciones constitutivas, la griega y la cristiana.

Xabier María Andónegui

Irala, 8

E-48012 BILBAO 